
inceleme (A2-B1 seviyesi). Aksaray Üniversitesi Sosyal Bilimler Enstitüsü Dergisi, 5(2), 196-211. doi: 10.38122/ased.52.6

Makale Geçmişi / Article History

Alindl (Received): 10/11/2021

Kabul edildi (Accepted): 29/12/2021

\title{
Yabancı Dil Olarak Türkçe Öğretiminde Dil Bilgisi Konularının Yunus Emre Şiirleriyle Pekiştirilmesi Üzerine Bir İnceleme (A2-B1 Seviyesi)
}

\section{Esra Merve OĞRAŞ}

Öz: Türkçe, köklü bir geçmişe sahip, dünyanın birçok bölgesinde yüzyıllarca konuşma ve yazı dili olarak kullanılan dünyanın en kadim dillerindendir. Yabancı dil olarak Türkçe öğretiminin tarihi, günümüzden farklı gerekçelerle de olsa oldukça eski dönemlere kadar uzanmaktadır. Kaşgarlı Mahmut'un "Dîvânu Lugati'tTürk” ve Ali Şîr Nevâyî'nin "Muhakemetü'l-Lugateyn” adlı eserleri, yabanc1 dil olarak Türkçeyi öğretmek amacıyla yazılmış eserlerden birkaçıdır. Bir dili öğrenmek için o dilin kültürel ögelerini de öğrenmek gerekmektedir. Anadolu'daki kültürü yabancı dil olarak Türkçenin öğretiminde kullanmak hem kültürümüzün dünyada tanitılmasına imkân sağlayacak hem de Türkçenin kültürel ögeler çerçevesinde öğretilmesine zemin hazırlayacaktır. Dil öğretiminde birçok yöntem kullanılmıştır. Günümüzde farklı teknik ve metotların kullanılması dil öğretiminde kolaylık ve çeşitlilik sağlamıştır. Şiirlerle bir dilin belli kurallarının yabancı dil olarak öğretimi günümüzde kullanılan yeni yaklaşımlardan biridir.Yunus Emre, insan sevgisini ve muhabbeti şiirlerinde öne çıaran Anadolu arifidir. O, ilahileriyle yalnızca Türk dilinin gelişmesine katkı sağlamamış, aynı zamanda sevgi üzerine kurduğu tasavvuf anlayışıyla insanlığın ortak değerler çerçevesinde bir arada yaşamasını hedefleyen mesajları şiirlerinde ortaya koymuştur. Bu bağlamda, onun şiirleri pek tabii olarak yabancı dil olarak Türkçe öğretiminde önemli bir kaynak teşkil etmektedir.Çalışmada, Mustafa Tatcı'nın "Yûnus Emre Dîvânı" adlı eseri esas alınarak Yunus Emre'nin bazı şiirleri günümüz Türkçesine aktarılmış ve yabancı dil olarak Türkçe öğretiminin A2 ve B1 seviyelerine uygun dil bilgisi çalışması yapılmıştır. Böylece hem Yunus Emre'yi ve onun şiirlerindeki kültürel unsurlar ve değerleri, değerleri uluslararası öğrencilere tanıtma imkânı oluşmuş hem de şiir ile dil bilgisi kurallarının öğretimi yabancı dil olarak Türkçe öğretiminde eğlenceli ve farklı bir teknik olarak uygulanmıştır.

Anahtar Kelimeler: Türkçe öğretimi, Yunus Emre, dil bilgisi.

\section{A Study on Reinforcing Grammar Topics in Teaching Turkish as a Foreign Language with} Yunus Emre Poems (A2-B1 Level)

Abstract: Turkish is one of the most ancient languages of the world, which hasa deep-rooleted history and has been used as a spoken and written language for centuries in many parts of the world. The history of teaching Turkish as a foreign language goes back to ancient times, albeit for different reasons than today. Kaşgarlı Mahmut's "Dîvânu Lugati't-Türk" and Ali Şîr Nevâyî's "Muhakemetü'l-Lugateyn"are some of the works written to teach Turkish as a foreign language. In 1rder to learn a language, it is necessary to learn the cultural elements of that language. Using the culture in Anatolia in the teaching of Turkısh as a foreign language will both enable the promotion of our culture in the world and prepare the ground fort he teaching of Turkish within the framework of cultural elements.Many methods have been used in language teaching. Today, the use of different tecniques and methods has provided convenience and diversity in language teaching. Teaching certain rules of a language with poems as a foreign language is one of the new approaches used today.Yunus Emre is an Anatolian scholar who emphasizes human love and affection in his poems. He not only contributed to the development of the Turkish language with his hymns, but also revealed in his poems the messages aimed at the coexistence of humanity within the framework of common values with the understanding of mysticism he founded on love. In this context, his poems naturally constitute an important source in teaching Turkish as a foreign language.In the study some of Yunus Emre's poems were translated into today's Turkish based on Mustafa Tatc1's "Yûnus Emre Dîvânı"and a gramer study suitable for A2 and B1 levels of teaching Turkish as a foreign language was conducted.Thus, it was possible to introduce Yunus Emre and the cultural elements

\footnotetext{
1 Öğr. Gör. Bursa Uludağ Üniversitesi, Türkçe Öğretimi Uygulama ve Araşsırma Merkezi (ULUTÖMER),
} emerveogras@uludag.edu.tr, ORCID:0000-0001-5041-7216 
and values in his poems to international students, and the teaching of poetry and grammar rules was applied as a fun and different tecnique in teaching Turkish as a foreign language.

Keywords: Turkish teaching, Yunus Emre, grammar

\section{Summary}

Language is the most effective and easiest way people use to communicate. Many theses have been put forwad about where, when and how languages emerged, but no answer that everyone agrees on has been found. Turkish is the one of the most ancient languages in the world when we look at the historical documents, sources, findings and evidence. Turkısh is one of the oldest languages in the world, which has a deep-rooted history and has been used as a spoken and written language in many different parts of the world for many years. It is also one of the most widely used and spoken languages in the world, as a communication tool that is spoken from Eastern Europe to the farthest reaches of Asia and allows millions of people to communicate. History of teaching Turkish as a foreign language, albeit for different reasons than today dates back to ancient times. Kaşgarlı Mahmut's"Dîvânu Lugati't-Türk"and Ali Şîr Nevâyî's"Muhakemetü'l-Lugateyn" named their achievement, for teach Turkish as a foreign language are some of the works written.

In order to learn a language, it is necessary to learn the cultural elements of that language. International students in our country for teach Turkish in the best and healthiest way in cultural transmission implementation point is important. Teaching Turkish which will be far from cultural values, only by sticking to printed book sources, will not serve the purpose, it will not make it possible to achieve the desired result at the point of cultural promotion and transfer. However, using the Turkish as a foreign language in teaching when it comes to understanding and living the culture in Anatolia will both enable our culture to be promoted around the world and prepare the ground for the teaching of Turkish within the framework of cultural elements. Many methods have been used in language teaching until today. One of these methods is to teach grammar to international students through poems. Today the use of different techniques and methods has provided convenience and diversity in language teaching. Teaching certain rules of a language as a foreign language through poems has become one of the new approaches that are in demand today. Although it has not become widespread in our country yet, examples of grammar teaching studies are increasing with this teaching method. This study was written in order to set an example for teaching grammar at A2-B1 levels to international students through Yunus Emre's hymns.

Yunus Emre 13-14. He is one of the greatest poets who lived in Anatolia between centuries and this land. He lived in difficult period in Anatolian history when famines, conflicts, wars and migrations prevailed. Despite all these difficult conditions, Yunus Emre healed hearts and cooled them with his chants. While doing this, he used Turkish in a "clean like mother's milk" way. Because 13-14. What poured out of his heart in the centuries can still be easily understood today. In this centuries it is seen that three different languages, Arabic, Persian and Turkish, were intertwined in Anatolia.

Yunus Emre brought a unique spirit to Turkish, knitted the language from beginning to end and helped to spread Sufism among the people who had not seen a school or a madrasah. The people always sang his poems both in poetry assemblies and in public places, composed his poems when necessary and spread Yunus Emre's poems in the cities and villages by translating them into language. Yunus Emre is the Anatolian poet who emphasizes human love and conversation forward in his poems. İt is necessary to know and apply the teachings of Yunus Emre in order to introduce the culture of our country to the world and to create a world that coincides with human values by using the sophisticated and unique language of civilization. Yunus Emre, not only contributed to the development of the Turkish language with his hymns, but also with his understanding of mysticism based on humanitarian values based on love, he put forward the messages that aim humanity to live together within the framework of common values without making any discrimination of belief, language and origin. In this context,his poems naturally constitute an important resource in teaching Turkish as a foreign language.

Many scientist have studied Yunus Emre and his poems. In the study, Mustafa Tatc1, who has come to the forefront as a scientist who has carried out many researches on Yunus Emre recently, published it from the book "Yunus Emre Dîvânı" by examining Yunus Emre's poems and some of his poems were translated into modern Turkish and a grammar study was carried out on aspects of teaching Turkish as a foreign language at A2 and B1 levels. Thus, it was possible to introduce Yunus Emre and cultural elements and values in his poems 
to international students and the teaching of poetry and grammar rules was applied as a fun and different tecnique in teaching Turkish as a foreign language.

As a result of the study, it has been observed that international students, interest in Yunus Emre, which has an important place in the Turkish world, has increased. In this context, the desire to conduct research on Yunus Emre's life and works aroused in the students. In addition, it is one of the results obtained that education with this method offers a more enjoyable and permanent learning climate for students. In our country especially in academic institutions the number of departments related to Turkish education for foreign students is increasing day by day and the number of international students is increasing in our country. Considering the place and structure of Turkish among the world languages, there are significant differences between the languages of international students in our country and our language. This situation complicates the teaching of grammar subjects in particular. In this context, the support and dissemination of the method we have applied with other studies will allow to overcome these difficulties in grammar teaching to a certain extent.

\section{GíRiş}

Türkçe, dünyanın en eski dillerinden biridir. Türkçe, kadim dönemlerden beri konuşma ve yazı dili olarak dünyanın çok farklı bölgelerinde kullanılmıştır. Bir dilin köklü geçmişinin olması o dile duyulan ilgiyi ve verilen önemi her daim canlı tutmuştur. Bu bağlamda, Türkçenin yabancı dil olarak öğretimi eski zamanlardan günümüze kadar sirayet etmiş bir durumdur. Kaşgarlı Mahmut ile başlayıp Ali Şîr Nevâyî ile devam eden bu süreçte yabancılara Türkçe öğretimi ile ilgili birçok eser yazılmıştır.

Yunus Emre, Anadolu irfanının ve kültürünün en önemli temsilcilerinden biridir. Onun ilahileri yüzyıllarca Anadolu insanının gönül dünyasını serinletmiş, ruhunu aydınlatmıştır. O, Türkçe tasavvuf ve mana dilinin kurucusudur. Dilimiz Yunus'un kalemiyle estetikleşmiş, edebileşmiş ve yeniden hayat bulup yayılmıştır (Tatc1, 1990: 2). Yunus'un dili XIII-XIV. yüzyıl Anadolu Türkçesinin bir örneği, divanı da o devrin bir dil hazinesidir (Gölpınarlı, 1965: XXXVI). Yunus Emre'nin şiirleri sahip olduğu mana dışında dil açısından da büyük ehemmiyet taşımaktadır. Onun günümüzden 7-8 asır önce vücuda getirdiği şiirler, bugün bile rahatlıkla anlaş1lacak biçimdedir. Bu yönüyle onun şiirleri Türkçe için büyük bir önem taşımaktadır. Çalışmada Yunus Emre’yi, onun su gibi akııı ve berrak Türkçesini yabancı bir dil olarak Türkçe öğretiminde kullanmak amaçlanmıştır. Böylece Yunus Emre’yi, şiirlerini, şiirlerindeki kültürel dokuyu yabancı öğrencilere tanıtırken şiirle dil bilgisi kurallarının öğretiminin pekiştirilmesi yabancı dil olarak Türkçe öğretiminde farklı bir teknik olarak uygulanma imkânı bulunmuştur.

Yabancı dil olarak Türkçe öğretiminde materyallerin kullanımı son derece önemlidir. Zira eski dönemlerde olduğu gibi tekdüze, ezberci bir yaklaşımla dil öğretmek artık çok eskide kalmış uygulamalardır. Günümüzde özellikle teknolojik gelişmelerin hayatımıza olan etkisinin artmasıyla dil öğretiminde birçok farklı yöntem ve teknik geliştirilmiştir. Dolayısıyla sadece kitap üzerinden hareket ederek dil öğretmek, istenilen neticeyi almayı zorlaştıracaktır. Yabancı dil öğretiminde süreci daha eğlenceli hâle getirmek ve dilimizi öğretirken kültürümüzü de tanıtmak yabancı bir dil olarak 
Türkçe öğretiminde önemli bir hedef hâline gelmiştir. Bu amaç doğrultusunda, söz konusu çalışma ile yabancı dil olarak Türkçe öğretiminde hem kültürel unsurlarımızı, değerlerimizi öğrencilerimize tanıtmak hem dersi sıkıcılıktan uzaklaştırıp öğrencileri aktif kılmak hem de daha verimli bir öğretim süreci oluşturulmak hedeflenmiştir.

Çalışmadaki şiirler, Mustafa Tatcı'nın "Yûnus Emre Dîvânı"’2 isimli eserinden alınmıştır. Çalışmadaki amaç, şiirlerin tümünün anlaşılması değil dil bilgisine dair unsurların pekiştirilmesinin sağlanmasıdır. Çalışmada, şiirlerin seçiminde yabancı öğrencilerin daha rahat anlayabilmesi için Yunus Emre'nin günümüz Türkçesine en yakın şiirlerinin seçilmesine özen gösterilmiştir. Divandan alınan beyit veya dörtlüklerin divandaki yerleri, şiir ve sayfa numaraları ile birlikte parantez içinde beyit veya dörtlüğün hemen yanında, öğrencilerin anlamını bilemeyecekleri düşünülen kelimelerin anlamları ise dipnot alanında verilmiştir. Şiirlerde, Yûnus Emre Dîvânı'ndan hareketle noktalama işaretlerine yer verilmemiştir. Yunus Emre Enstitüsü tarafından "Yedi İklim Türkçe”3 ders kitabındaki A2-B1 seviyelerini içeren dil bilgisi konularından bazıları bu ders kitabındaki anlatım sırasına göre ele alınmıştır.

Çalışmada yer verilen A2 dil bilgisi konuları şu şekildedir:

$$
\begin{aligned}
& \text { 1.1. Belirsiz Geçmiş Zaman (-mIş) } \\
& \text { 1.2. Geniş Zaman (-r, -Ar) } \\
& \text { 1.3. İsim Fiil (-mA) } \\
& \text { 1.4. Zarf Fiil (-mAdAn, -Ip) } \\
& \text { 1.5. Yeterlik Birleşik Fiili (-Abil) } \\
& \text { 1.6. -mAk için }
\end{aligned}
$$

Çalışmada ele alınan B1 konuları şu şekildedir:

$$
\text { 1.1. Bildirme Eki (-Dir) }
$$

$$
\text { 1.2. Dilek - Şart Kipi (-sA) }
$$

\footnotetext{
${ }^{2}$ Ayrıntılı bilgi için bkz. Tatcı, M. (YTY). Yûnus Emre Dîvânı. Eskişehir: Kültür ve Turizm Bakanlığı Kütüphaneler ve Yayımlar Genel Müdürlüğü.

${ }^{3}$ Ayrıntılı bilgi için bkz. Gültekin, İ. \& Kalfa, M. \& Atabey, İ. \& Mete, F. \& Eryiğit, A. \& Kılıç, U. (2015). Yedi İklim Türkçe A2. Ankara: Türkiye Diyanet Vakfı Yayınları.

Gültekin, İ. \& Kalfa, M. \& Atabey, İ. \& Mete, F. \& Eryiğit, A. \& Kılıç, U. (2015). Yedi İklim Türkçe B1. Ankara: Türkiye Diyanet Vakfi Yayınları.
} 
1.3. - mAk gerek

1.4. Sifat Fiil (-An)

\section{A2 Kuruna Ait Dil bilgisi Konuları ve İlgili Şiir Kısımlarından Örnekler}

\subsection{Belirsiz Geçmiş Zaman -mIş}

$\mathrm{Bu}$ ek görülmeyen geçmiş zamanda yapılan bir hareketi haber veren şekil ve zaman ekidir. Geçmişte olan ve konuşanın, o hareketi bildirenin önünde cereyan etmeyen hareket demektir. Konuşanın gözü, bilgisi, şuuru önünde vuku bulmamıştır. Konuşan onu sonradan duymuş, öğrenmiş veya onun sonradan farkına varmıştır (Ergin, 2006: 300).

Çalap nurdan yaratmış cânını Muhammed'in

Âleme rahmet saçmış adını Muhammed'in $\left(145 / 1\right.$, s.115) ${ }^{4}$

Dostum demiş yaratmış hem onun kaydın yimiş

Ümmetten yana koymuş yönünü Muhammed'in (145/2, s.115)

Dünya malın tutmamış hiç emanet artmamış

Terzi ekip biçmemiş elbisesini Muhammed'in (145/4, s.115)

Yukarıda Yunus Emre'nin şiirlerinden alınan beyitlerde fiillere getirilen ve eylemin yapılış zamanını geçmişte belirsiz kılan zaman eki olan “-mIş” ekinin örnekleri verilmiştir. Bu örneklerden hareketle uluslararası öğrenciler, A2 müfredatında yer alan "belirsiz geçmiş zaman” konusunu ezberci bir zihniyet dişında şiirler üzerinden daha rahat idrak edebileceklerdir.

\subsection{Geniş Zaman -r, -Ar}

Geniş zaman, her zamanı içine alan, fiilin her zaman ortaya çıktığını ve çıkacağını ifade eden zamandır. Geniş zaman eklerinin asıl fonksiyonu bu "her zaman" '’1 ifade etmektedir. Geçmiş zamanda başlayıp şimdiki zamanda devam eden, böylece daimilik vasfını kazanmış olan hareketler için bu zaman kullanıldığı gibi, gelecek zamanda olacak veya yapılacak hareketler için de bu çekime başvurulabilir (Ergin, 2006: 291).

Severim ben seni candan içeri

Yolum ötmez ${ }^{5}$ bu erkândan ${ }^{6}$ içeri (290/1, s.234)

Beni benden alana ermez elim

Kadem kim basa sultandan içeri (290/4, s.234)

Süleyman kuşdili bilir dediler

Süleyman var Süleyman'dan içeri (290/9, s.234)

4 “Yûnus Emre Dîvânı” neşrinden alınan beyitlerin bulunduğu sıra manzume numarasının ardına eklenmiş, ayrıca beytin divân neşrinde geçtiği yerin sayfa numarası belirtilmiştir.

${ }^{5}$ Ötmek: Geçmek (Yûnus Emre Dîvânı, s. 393).

${ }^{6}$ Erkân: Esaslar, âdetler (Yûnus Emre Dîvânı, s. 363). 
Sülûk ${ }^{7}$ seyir eden aşkın eline

Nice mezhep olur dinden içeri (290/10, s.234)

O bir dilber durur hiç yok nişân $1^{8}$

Nişan olur mu nişândan içeri (290/12, s.235)

$$
\text { * }
$$

Aşkın aldı benden beni

Bana seni gerek seni

Ben yanarım dün ü günü

Bana seni gerek seni (381/1, s.311)

$\mathrm{Ne}$ varlığa sevinirim

Ne yokluğa yerinirim

Aşkın ile avunurum

Bana seni gerek seni (381/2, s.311)

Aşkın âşıklar öldürür Aşk denizine daldırır

Tecelliyle doldurur

Bana seni gerek seni (381/3, s.311)

Yunus çağırırlar adım

Gün geçtikte artar odum

İki cihanda maksudum

Bana seni gerek seni (381/10, s.312)

*

Ben yürürüm yana yana

Aşk boyadı beni kana

$\mathrm{Ne}$ âkilem ${ }^{9}$ ne divâne

Gel gör beni aşk n'eyledi (404/2, s.328)

Ben yürürüm ilden ile

Dost sorarım dilden dile

Gurbette hâlim kim bile

Gel gör beni aşk n'eyledi (404/3, s.328-329)

Gurbet ilinde yürürüm

Dostu düşümde görürüm

Uyanıp Mecnûn olurum

Gel gör beni aşk n'eyledi (404/5, s.329)

Gâh ${ }^{10}$ tozarım yerler gibi

Gâh eserim yeller gibi

Gâh çağlarım seller gibi

Gel gör beni aşk n'eyledi (404/6, s.329)

\footnotetext{
${ }^{7}$ Sülûk: Manevi yolculuk (Yûnus Emre Dîvân1, s. 401).

${ }^{8}$ Nişân: İz, âlamet (Yûnus Emre Dîvân1, s. 392).

9 Âkil: Akıllı (Yûnus Emre Dîvânı, s. 344).

${ }^{10}$ Gâh: Ara sıra (Yûnus Emre Dîvânı, s. 366).
} 
Akarsu gibi çağlarım

Dertli ciğerim dağlarım

Şeyhim anıp ağlarım

Gel gör beni aşk n'eyledi (404/7, s.329)

*

Ben bir acep ile geldim kimse halim bilmez benim

Ben söylerim ben dinlerim kimse dilim bilmez benim (175/1, s.139)

Benim dilim kuş dilidir benim ilim dost ilidir

Ben bülbülüm dost gülümdür bilin gülüm solmaz benim (175/2, s.139)

O dost bana gelsin demiş sundum kadeh alsın demiş

Aldım kadeh içtim şarap gayrı gönlüm ölmez benim (175/3, s.139)

Ne durum var ne durağım hiç yerde yoktur kararım

Hakk'a münacat etmeye belli yerim olmaz benim (175/4, s.139)

Sor durduğum yeri bana gelirsen gösterem sana

Bir zerrece Hak'dan ayrı gözüm nesne görmez benim (175/5, s.139)

Tur Dağında bir tecelli gör Musa'ya neler kıldı

Yunus der ki Hak katında sözüm geri kalmaz benim (175/6, s.139)

Yunus Emre Divânı'ndan alınan yukarıdaki örnek beyitlerde uluslararası öğrencilerin sıklıkla karşılaştığı geniş zaman ekleri olan “-r, -Ar, -Ir, -mAz” eklerinin kullanımı görülmektedir. Bu eklerde hem fiile gelen geniş zaman ekleri hem de söz konusu fiillerin anlamları beyitlerin bağlamı dikkate alınarak görülebilecektir. Uluslararası öğrencilerin bu şekilde şiir içerisindeki örneklerden hareketle kavramsal düzeylerinin artmasına da katkı sağlanacaktır.

\section{3. İsim-Fiil}

Türkçede -mAk - mA -Iş ekleriyle yapılan üç türlü isim-fiil vardır. İsim-fiillerde kişi anlamı olmadığı gibi zaman anlamı da yoktur (Banguoğlu, 2007: 420).

Yönelme durum ekini almış olan -mA'lı isim-fiil, cümlede ilgili bulunduğu ögeye ya yükleme ya da doğrudan doğruya yönelme ilişkisi ile bağlanan veya yüklemle "bir şey için, bir şey maksadıyla" anlamında yönelme ilişkisi kuran bir yer tamlayıcısı görevindedir (Korkmaz, 2009: 888).

Benim bunda kararım yok ben bundan gitmeye geldim

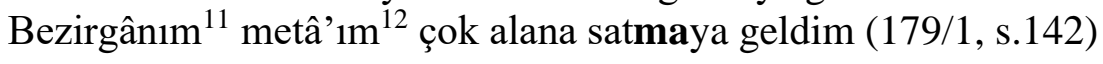

Ben gelmedim dava için benim için sevi için

Dostun evi gönüllerdir gönüller yapmaya geldim (179/2, s.142)

\footnotetext{
${ }^{11}$ Bezirgân: Tüccâr (Yûnus Emre Dîvânı, s. 351).

${ }^{12}$ Metâ': Menfaat, kıymetli şey (Yûnus Emre Dîvânı, s. 386).
} 
Dost esriği deliliğim âşıklar bilir neliğim

Devşirerek ikiliğim birliğe yetmeye geldim (179/3, s.143)

O hâcemdir ben kuluyum dost bahçesi bülbülüyüm

O hâcemin bahçesinde şâd olup ötmeye geldim (179/4, s.143)

Bunda bilişmeyen canlar onda bilişemez onlar

Bunda bilişip dostla halim arz etmeye geldim (179/5, s.143)

Yunus Emre âşık olmuş mâşuka derdinden ölmüş

Gerçek erin kapısında halim arz etmeye geldim (179/6, s.143)

Söz konusu beyitler dikkate alınarak A2 seviyesine ait bir dil bilgisi konusu olan ve eylem anlamını muhafaza eden isim-fiil eklerinden biri olan $-\mathrm{mA}$ ekinin, yönelme hâl eki ile bir arada kullanımı uluslararası öğrencilere gösterilebilecektir.

\subsection{Zarf-fiil}

Zarf-fiiller bir yanıyla fiil, bir yanıyla da zarf özelliği taşıyan gramer kategorileri oldukları için, fiil yönleriyle yalnızca hareket ve zaman kavramını karşılar; zarf yönleriyle de bir oluş ve kılışın durum ve tarzını bildirme niteliğine sahiptirler. Bu nedenle cümlede, şahsa ve zamana bağlı bir yargı bildirmeyen; ancak yargı bildiren fiiller yanında, onlardaki oluş ve kılışın durum ve tarzını belirleyen zarf görevi yüklenirler (Korkmaz, 2009: 983).

\subsection{1. $-\mathrm{Ip} / \mathrm{Up}$}

İki hareketin birbiri ardınca veya aynı zamanda gerçekleştiğini gösterirler (Banguoğlu, 2007: 429).

Canım ben ondan bunda ezeli âşık geldim

Aşkı kılavuz tuttum aşka ulaşıp geldim (181/1, s.144)

Değilim kâl u kîlde yâ yetmiş iki dilde

Yad olup bana bu ilde onda bilişip geldim (181/2, s.144)

Geçtim hod-bîn ilinden el çektim dükelinden

O ikilik bâbından birliğe bitüp geldim (181/3, s.144)

Dört kişidir yoldaşım vefâ-dârım râz-daşım

Üçüyle hoştur başım birine buşup geldim (181/4, s.144)

O dördün birisi can biri din biri iman

Biri nefsimdir düşman anda savaşıp geldim (181/5, s.144)

Bir k1lı kırk yardılar birin yol gösterdiler

Bu mülke gönderdiler o yola düşüp geldim (181/6, s.144)

Aşk şerbetinden içtim on iki irmak geçtim

Denizler bendin deştim ummandan taşıp geldim (181/7, s.144) 
Ben ondan geldim onda yine varırım ona

Ben ona varasımı ona danışıp geldim (181/8, s.144)

Azrail ne kişidir kasd edesi canıma

Ben emanet 1ssıyla onda bitrişüp geldim (181/9, s.144)

Aradım çıktım bir uca eğlendim teferrüce

Eren soyun soylayıp o soya düşüp geldim (181/10, s.144)

Yunus Emre'ye ne gam âşık melamet bed-nâm ${ }^{13}$

Küfrüm imana şol dem onda değişip geldim (181/10, s.145)

\subsection{2. -mAdAn}

İç cümlenin gerçekleşmeyeceğini yalnız baş cümlenin gerçekleşeceğini anlatırlar. Ancak bu zarf-fiiller bir başka anlatımda esas fiilin zamanca önceliği anlamında da kullanılırlar (Banguoğlu, 2007: 432).

Gel gidelim can durmadan

Sûret terkini vurmadan

Araya düşman girmeden

Gel dosta gidelim gönül (160/2, s.127)

Ölüm haberi gelmeden

Ecel yakamız almadan

Azrail hamle k1lmadan

Gel dosta gidelim gönül (160/9, s.128)

Yukarıda yer alan beyitler, zarf-fiil eklerinin kullanıma örnek teşkil etmektedir. İlgili eklerin redif parçası olarak şiirde tekrarlanması ile A2 seviyesinde anlatılan -Ip/Up ve -mAdAn zarf-fiil ekleri, cümleye kattığı hareket ve zaman kavramlarının uluslararası öğrencilere öğretimi bu ve benzeri örneklerle desteklenebilecektir.

\subsection{Yeterlik Birleșik Fiili (-Abil)}

Yeterlik fiilleri kimsenin yeterliğini, sözü geçen kılışın veya oluşun mümkün veya muhtemel olduğunu anlatırlar. Yeterlik fiilinin olumsuz şekli de olumlusuna paralel olarak hemen bütün fiil çekimi ve yatık fiiller kalıplarına girer (Banguoğlu, 2007: 490).

Niceler bu dünyada günahını çekemez

Ömrü geçer yok yere ey dirîgâ ${ }^{14}$ duyamaz $(105 / 1$, s.83)

Bir nice kişilerin gaflet gözün bağlamış

Hak yoluna der isen bir yufkaya ${ }^{15}$ kıyamaz (105/2, s.83)

\footnotetext{
${ }^{13}$ Bed-nâm: Adı kötüye çıkmış (Yûnus Emre Dîvânı, s. 349).

${ }^{14}$ Dirîgâ: Ne kadar yazık (Yûnus Emre Dîvânı, s. 360).

${ }^{15}$ Yufka: İnce, nazik (Yûnus Emre Dîvân1, s. 416).
} 
Bu dünya bir gelindir yeşil kızıl donanmış

Kişi yeni geline bakıp doyamaz (105/3, s.83)

Ey nice aslanları alır aktarır ölüm

Azrail pençesine bir yoksulca döyemez ${ }^{\mathbf{1 6}}$ (105/4, s.83)

Var şimdi miskin Yunus uryan olup gir yola

Yüz zırhlı gelirse yalıncağ ${ }^{17}$ soyamaz $(105 / 5$, s.83)

Yunus Emre'nin şiirlerinde yer alan yeterlik birleşik fiilinin olumsuz şekilleri, sade dille ifade edilmesi yönüyle yabancı dil öğretiminde rahatlıkla kullanılabilir örnekleri içerir niteliktedir.

\section{6. -mAk için}

İçin edatı ile birleşen -mAk'lı hareket adı, yükleme “maksat, gaye, hedef” bildirme işleviyle bağlanır (Korkmaz, 2009: 875).

Gelin bugün yanalım yarın yanmamak için

Ölelim ölmezken yine ölmemek için (251/1, s.204)

Tartalım günahımız arttıralım ahımız

Edelim hesabımız hesap olmamak için (251/2, s.204)

Erenlere gidelim eteklerini tutalım

Bugün öyle edelim yolda kalmamak için (251/3, s.204)

Bak göresin dünyaya geldiğini bil neye

İş bu fani dünyaya mağrur olmamak için (251/4, s.204)

Yunus yok dünya tadı çünkü faniymiş adı

Muhammed zindan dedi biz şâd olmamak için (251/5, s.204)

A2 dil bilgisi konularından biri olan isim-fiil ve için edatı cümleye amaç, hedef anlamları katar. Günlük yaşamda sıkça kullanılan bu yapı öğrencilerin şiirler vasıtasıyla Türkçeyi daha rahat öğrenmesini, kavramasını ve konuşma becerilerini geliştirmesini mümkün kılabilir.

\section{B1 Kuruna Ait Dil bilgisi Konuları ve İlgili Şiir Kısımlarından Örnekler}

\section{1. -DIr Bildirme Eki}

Bildirme eki alan, ek-fiil ile çekime giren yahut yüklem görevindeki bir adla anlam ilişkisi bulunan -mAk'lı isim-fiil, cümlede yargı bildiren bir yüklem görevindedir (Korkmaz, 2009: 880).

İlim ilim bilmektir ilim kendin bilmektir

Sen kendini bilmezsen ya nice okumaktır (91/1, s.73)

Okumaktan ma'na ne kişi Hakk’1 bilmektir

\footnotetext{
${ }^{16}$ Döymek: Tahammül etmek, dayanmak (Yûnus Emre Dîvânı, s. 360).
}

17 Yalıncak: Çıplak (Yûnus Emre Dîvânı, s. 412). 
Çün okudun bilmezsin ha bir kuru emektir $(91 / 2$, s.73)

Okudum bildim deme çok tâ'at kıldım deme

Eri Hak bilmez isen abes yere yelmektir (91/3, s.73)

Dört kitabın manisi bellidir bir elifte

Sen elif dersin hoca manas1 ne demektir $(91 / 4$, s.73)

Yunus der hoca gerekse var bin hacca

Hepisinden iyice bir gönüle girmektir $(91 / 5$, s.74)

B1 seviyesinde işlenen geniş zamanı ifade eden -DIr bildirme eki yukarıdaki örnek kullanımlarla uluslararası öğrencilere öğretilebilir.

\subsection{Dilek-Şart Kipi}

İyelik kökenli şahıs ekleri alarak çekime giren dilek-şart kipi, "şart” ve "dilek, istek, niyet bildirme" gibi iki yönlü ve birbirinden farklı iki temel görev yüklenmiştir. Dilek-şart kipi şart kullanımda "şart” görevi yüklendiğinde bir yargı bildirmediği hâlde “dilek” görevi kullanıldığında tam bir yarg1 bildirmektedir (Korkmaz, 2009: 676).

Yüz bin cefâ k1lsan bana

Senden yüzün döndürmezem

Canım dahi alır isen

Senden yüzüm döndürmezem (219/1, s.180)

Kiliseye dersen girem

Nâkûs ${ }^{18}$ dahi dersen çalam

Âşıklara yoktur kalem

Senden yüzüm döndürmezem (219/3, s.180)

Yunus gerçek âşık isem

Hak yoluna sadik isem

Hidmetlere layık isem

Senden yüzüm döndürmezem (219/5, s.180)

*

Sensin benim canım canı sensiz kararım yoktur

Uçmak'da sen olmazsan vallah nazarım yoktur (52/1, s.43)

Baksam seni görür özüm söylersen sensin sözüm

Seni gözetmekten dahi yigrek ${ }^{19}$ şikârım yoktur (52/2, s.43)

Söylersem dilimdesin ger ${ }^{20}$ tek dursam gönlümdesin

Gönlüm gözüm seni sever başka nigârım ${ }^{21}$ yoktur (52/3, s.43)

Çünkü ben beni unutmuşum şöyle ki sana gitmişim

\footnotetext{
18 Nâkûs: Kiliselerde çalınan çalgı (Yûnus Emre Dîvânı, s. 390).

${ }^{19}$ Yigrek: Daha iyi, üstün (Yûnus Emre Dîvânı, s. 415).

${ }^{20}$ Ger: Eğer (Yûnus Emre Dîvânı, s. 367).

${ }^{21}$ Nigâr: Sevgili (Yûnus Emre Dîvânı, s. 391).
} 
Ne kâlde ne haldeysem her dem kararım yoktur (52/4, s.43)

Eğer beni Cercis $^{22}$ gibi yetmiş kez öldürürsen

Dönem geri sana varam zirâ ki ârum yoktur $(52 / 5, \mathrm{s.43})$

*

Miskînlikten ${ }^{23}$ buldular kimde erlik var ise

Merdivenden ittiler yüksekten bakar ise (299/1, s.243)

Gönül yüksekte gezer dem-be-dem ${ }^{24}$ yoldan azar

Taş yüzüne yol s1zar içinde ne var ise (299/2, s.243)

Ak sakallı pîr koca bilmez ki hali nice

Emek yemesin hacca bir gönül yıkar ise (299/3, s.243)

Sağır işitmez sözü gece sanır gündüzü

Kördür münkirin gözü âlem münevver ise (299/4, s.243)

Gönül Çalab' ${ }^{25}$ tahtı gönüle Çalap bahtı

İki cihân bed-bahtı kim gönül yıkar ise (299/5, s.243)

Sen seni ne sanırsan ayrığa da onu san

Dört kitabın manisi budur eğer var ise (299/6, s.243)

Bildik gelenler geçmiş konanlar geri göçmüş

Aşk şarabından içmiş kim mani tutar ise (299/7, s.243)

Yunus yoldan 1 rmasin ${ }^{26}$ yüksek yerde durmasın

$\operatorname{Sin}^{27}$ ile Sırât görmesin sevdiği didar ise (299/8, s.243)

Dilek-şart kipinin Yunus Emre'nin şiirlerinde oldukça sık karşımıza çıkması bu dil bilgisi konusunun onun şiirlerden hareketle öğrencilere öğretilmesine ve çok defa pratik yapılmasına imkân sağlamaktadır.

\section{3. -mAk gerek}

-mAk hareket adı ile birleşen "lâzım, lâzımdır, lâzım gel-, gerek-, icap et-, zorunda ol-" gibi yüklem veya birleşik fiiller gereklilik kipinin yerini tutar (Korkmaz, 2009: 881).

Dünyaya gelen kişiler yola bile gelmek gerek

Ölümünü anıp anıp dün ü gün ağlamak gerek (137/1, s.109)

Bu dünya kahır evidir hem baki değil fânidir

Aldanıp kanma buna tez tövbeye gelmek gerek (137/2, s.110)

\footnotetext{
${ }^{22}$ Cercis: İsâ Peygamberden sonra geldiği rivayet edilen ve onun şeriatine uyan bir peygamberdir. Kur'ân'da ismi geçmez. Yetmiş kez öldürülmüş her öldüğünde yeniden dirilmiştir (Yûnus Emre Dîvânı, s. 355).

${ }^{23}$ Miskînlik: Metinde "Fenafillah", benlik terki anlamlarındadır (Yûnus Emre Dîvânı, s. 387).

${ }^{24}$ Dem-be-dem:Vakit, vakit. Daima (Yûnus Emre Dîvânı, s. 358).

${ }^{25}$ Çalab: Allah (Yûnus Emre Dîvânı, s. 356).

${ }^{26}$ Irmak: Uzaklaştırmak, ayırmak (Yûnus Emre Dîvânı, s. 374).

${ }^{27}$ Sin: Mezar (Yûnus Emre Dîvânı, s. 400).
} 
Ne durur dünya çokluğu eşkere ${ }^{28}$ durur yokluğu

Varlık sarayın hâkikat ahireti bilmek gerek (137/3, s.110)

Gel şimdi dur bu faniden mahrum kalmadan bâkiden

Ta'ât ${ }^{29}$ kılıp bu dünyadan kullar nasip almak gerek (137/4, s.110)

Korkarsan sen tamudan (gel) alçak ol kamudan

O gün ince köprüden (bil) kamular geçmek gerek (137/5, s.110)

Geçip gitmek diler isen ya düşmeyeyim der isen

Şu kazandığın malını Tanrı için vermek gerek (137/6, s.110)

Kazandığını ver yoksulları hoş gör

Hak hazretine var oddan o kurtulmak gerek (137/7, s.110)

Kur'an diyor ki vattâku ${ }^{30}$ yine diyor ki tezra' û

Tembel olup oturma tez tövbeye gelmek gerek (137/8, s.110)

Yunus'un sözü şiirden ama aslıdır kitaptan

Hadis ile dinene çok sadık olmak gerek (137/9, s.110)

Ne edelim bu dünyayı n'eyleyip ne etmek gerek

Daima aşk eteğin komayıp tutmak gerek (141/1, s.112)

Çalab'ım bu dünyayı kahır için yaratmış

Gerçeğin gelenlerin kahrını yutmak gerek (141/2, s.112)

O yarınki yollara onda yoldaş isteyen

Bu dünyada dostunu kılavız tutmak gerek (141/3, s.113)

Uçmak uçmak dediğin kulların yeltediğin ${ }^{31}$

Uçmağın sermayesi bir gönül etmek gerek (141/4, s.113)

Erenlerin âhına dağ taş katlanamadı

Kalkanı demir ise okları atmak gerek (141/5, s.113)

Yunus el nazarında taze güller açılmış

Sen gerçek bülbül isen nazarda ötmek gerek (141/6, s.113)

Gereklilik kipi anlamı taşıyan -mAk gerek yapısı, Yunus Emre'nin şiirlerinde çokça kullanılmış bir dil bilgisi yapısıdır. Yabancı dil öğretiminde gereklilik kipi olarak öğrencilere aktarılan -mAlI dışında bu anlama ve göreve sahip başka bir dil bilgisi yapısının örneklerinin

${ }^{28}$ Eşker: Âşikâr, açık,meydanda (Yûnus Emre Dîvânı, s. 364).

29 Ta'ât: Allah'ın emirlerini yerine getirme (Yûnus Emre Dîvânı, s. 403).

30 Vattâku: Sakınınız, sakınsaydınız anlamlarına gelen bir söz olup pek çok âyette geçmektedir (Yûnus Emre Dîvânı, s. 411).

${ }^{31}$ Yeltemek: Heveslendirmek (Yûnus Emre Dîvânı, s. 414). 
sunulması, Yunus Emre'nin şiirlerinin uluslararası öğrencilere Türkçe öğretiminde önemli bir kaynak oluşturduğu gerçeğini ortaya koyar niteliktedir.

\subsection{Sifat Fiil}

Sıfat fiiller bir yanları ile sıfat, bir yanları ile fiillerdir. Fiil özellikleri dolayısıyla kendilerinde var olan hareket ve zaman kavramlarını, ad oldukları sıfata aktararak varlıkları ve nesneleri hareket ve zaman gösterme özellikleri ile geçici olarak vasıflandırırlar (Korkmaz, 2009: 909).

\subsection{1.-An:}

Geniş zamanı ifade eden bu ek eskiden beri en geniş ölçüde kullanılan bir partisip ekidir (Ergin, 2006: 334).

Biz dünyadan gider olduk kalanlara selam olsun

Bizin için hayır dua kılanlara selam olsun (231/1, s.188)

Ecel büke belimizi söylemeye dilimizi

Hasta iken halimizi soranlara selam olsun (231/2, s.189)

Tenim ortaya açıla yakasız gömlek biçile

Bizi bir ar1 vechile ${ }^{32}$ yuyanlara ${ }^{33}$ selam olsun (231/3, s.189)

Bunda hep gelenler gider herkes gelmez yola gider

Bizim halimizden haber soranlara selam olsun (231/7, s.189)

Âşık odur Hakk'1 seve Hak derdine kıla deva

Bizim için hayır dua kılanlara selam olsun (231/8, s.189)

Miskîn Yûnus söyler sözü kan yaş ile doldu gözü

Bilmeyen ne bilsin bizi bilenlere selam olsun (231/9, s.189)

*

Canını aşk yoluna vermeyen âşık mıdır

${ }^{34}$ Cehd eyleyip o dosta ermeyen âşık mıdır (36/1, s.30)

Aşk kadehinden içip nefs dileğinden geçip

Hak yoluna er gibi durmayan âşık mıdır (36/2, s.30)

Dost sevgisin gönülde can ile berkitmeyen ${ }^{35}$

${ }^{36}$ Tûl-1 emel defterin dürmeyen âşık midır (36/3, s.30)

\footnotetext{
${ }^{32}$ Vech: Yüz (Yûnus Emre Dîvânı, s. 411).

${ }^{33}$ Yumak: Y1kamak (Yûnus Emre Dîvânı, s. 416).

${ }^{34}$ Cehd (a): Fazla gayret, güç-kuvvet sarf etme, azim (Yûnus Emre Dîvânı, s. 354).

${ }^{35}$ Berkitmek: Kuvvetlendirmek, sağlamlaştırmak (Yûnus Emre Dîvânı, s. 350).

36 Tûl-1 emel: Hirs, tamah, tükenmez arzu (Yûnus Emre Dîvânı, s. 408).
} 
Dâyim riyâzât ${ }^{37}$ çekip halvet ${ }^{38}$ lerde diz çöküp

Hak didârı eserin görmeyen âşık mıdır (36/4, s.30)

Aşka tanışık sığmaz değme can göğe ağmaz

Pervâne gibi oda yanmayan âşı mıdır $(36 / 5, \mathrm{~s} .30)$

Kişi dertli olacak derman isteyen olur

Kendi derdi dermânın sormayan âşık mıdır (36/6, s.30)

Ey Yunus sen dostunun cefâsina katlan

Yüreğine aşk okunu vurmayan âşı mıdır (36/7, s.30)

Eylem anlamlarını yitirmeyip cümlede sıfat görevinde kullanılabilen bu gramer konusu, B1 seviyesindeki öğrencilere şiirler vasıtasıyla aktarılıp onların öğrenme deneyimlerini çeşitlendirmeye, daha farklı ve kalıcı bir öğrenme iklimine sahip olabilmelerine imkân sağlayabilir.

\section{SONUÇ}

Türk dili, bir iletişim aracı olarak dünyanın en çok kullanılan dillerinden biridir. Uluslararası öğrencilere, Türk dilini öğretirken kültürel aktarımın da uygulanması son derece önemlidir. Sadece teori odaklı, ezbere dayalı bir Türkçe öğretimi yerine dinamik, eğlenceli, ülkemizin kültürel unsurlarını da yansıtabilecek bir öğretim metoduyla hem öğrencilerin dersten sıkılmasının önüne geçilecek hem de tekdüze bir öğretimden uzaklaşılacaktır.

Yunus Emre, Türkçenin tüm güzelliklerini, dil öğretiminde gerek duyulan dil bilgisi unsurlarına dair örnekleri şiirlerinde oldukça açık ve anlaşılır bir dille ifade etmiştir. Onun şiirleri Türkçenin arkaik sözcüklerini, Eski Anadolu Türkçesi döneminin dil unsurlarını, deyim ve atasözlerini kısacası Türkçenin tüm duru ve güzel yapısını içinde barındırmaktadır. Bu özellikler yabancı dil olarak Türkçe öğretiminde Yunus Emre şiirlerinin kullanılmasını kolaylaştırmış, önemli hâle getirmiştir. Bu bağlamda çalışmada, Yunus Emre'nin şiirlerinin yabancı dil olarak Türkçenin öğretiminde A2-B1 seviyeleri dil bilgisi konularında nasıl kullanılabileceği üzerinde durulmuş, Yunus Emre şiirlerinin tümünün anlaşılması değil, A2-B1 kurlarında yer alan dil bilgisi konularını içeren eklerin ele alınıp pekiştirilmesi hedeflenmiştir.

${ }^{37}$ Riyâzât: Tasavvufta nefsin isteklerini bertaraf etmek için aç kalma, az ile kanaat etme (Yûnus Emre Dîvânı, s.

${ }^{38}$ Halvet: Yalnızlık (Yûnus Emre Dîvânı, s. 370). 


\section{KAYNAKÇA}

Banguoğlu, T. (2007). Türkçenin Grameri. Ankara: Türk Dil Kurumu Yayınları.

Ergin, M. (2006). Türk Dil Bilgisi. İstanbul: Bayrak Yayınları.

Gölpınarlı, A. (1965). Yunus Emre Risâlat al- Nushiyye ve Dîvân. İstanbul: Eskişehir Turizm ve Tanıtma Derneği Yayını.

Gültekin, İ. \& Kalfa, M. \& Atabey, İ. \& Mete, F. \& Eryiğit, A. \& Kılıç, U. (2015). Yedi İklim Türkçe A2. Ankara: Türkiye Diyanet Vakfı Yayınları.

Gültekin, İ. \& Kalfa, M. \& Atabey, İ. \& Mete, F. \& Eryiğit, A. \& Kılıç, U. (2015). Yedi İklim Türkçe B1. Ankara: Türkiye Diyanet Vakfı Yayınları.

Korkmaz, Z. (2009). Türkiye Türkçesi Grameri Şekil Bilgisi. Ankara: Türk Dil Kurumu Yayınları.

Tatcı, D. M. (1990). Yunus Emre Divânı II Tenkitli Metin. Ankara: Kültür Bakanlığı Yayınları.

Tatc1, M.(YTY). Yûnus Emre Dîvânı. Eskişehir: Kültür ve Turizm Bakanlı̆̆ı Kütüphaneler ve Yayımlar Genel Müdürlüğü.

Tatc1, M. (1990). Yûnus Emre Dîvânı (İnceleme-Metin I) Doktora Tezi. Gazi Üniversitesi Sosyal Bilimler Enstitüsü Türk Dili ve Edebiyatı Eğitimi Ana Bilim Dall. Ankara: Yükseköğretim Kurulu Dokümantasyon Merkezi. 